\title{
Application of transient elastography in nonalcoholic fatty liver disease
}

\author{
Xinrong Zhang ${ }^{1,2}$, Grace Lai-Hung Wong ${ }^{1,2}$, and Vincent Wai-Sun Wong ${ }^{1,2}$ \\ ${ }^{1}$ Department of Medicine and Therapeutics, ${ }^{2}$ State Key Laboratory of Digestive Disease, The Chinese University of Hong Kong, Hong \\ Kong
}

Nonalcoholic fatty liver disease (NAFLD) is currently the most common chronic liver disease worldwide. Although it has become one of the leading causes of cirrhosis and hepatocellular carcinoma in the Western world, the proportion of NAFLD patients developing these complications is rather small. Therefore, current guidelines recommend noninvasive tests for the initial assessment of NAFLD. Among the available non-invasive tests, transient elastography by FibroScan ${ }^{\circledast}$ (Echosens, Paris, France) is commonly used by hepatologists in Europe and Asia, and the machine has been introduced to the United States in 2013 with rapid adoption. Transient elastography measures liver stiffness and the controlled attenuation parameter simultaneously and can serve as a one-stop examination for both liver steatosis and fibrosis. Liver stiffness measurement also correlates with clinical outcomes and can be used to select patients for varices screening. Although obesity is a common reason for measurement failures, the development of the XL probe allows successful measurements in the majority of obese patients. This article reviews the performance and limitations of transient elastography in NAFLD and highlights its clinical applications. We also discuss the reliability criteria for transient elastography examination and factors associated with false-positive liver stiffness measurements. (Clin Mol Hepatol 2020;26:128-141)

Keywords: Liver cirrhosis; Fatty liver; Metabolic syndrome; Obesity; Diagnostic imaging

\section{INTRODUCTION}

Non-alcoholic fatty liver disease (NAFLD) is currently the most common chronic liver disease worldwide.' In the United States, nonalcoholic steatohepatitis (NASH), the active form of NAFLD with faster fibrosis progression, has already become one of the leading causes of cirrhosis and hepatocellular carcinoma. ${ }^{2}$ An up- dated systematic review and meta-analysis also shows that the prevalence of NAFLD in Asia has increased from $25 \%$ between 1999 and 2005 to 34\% between 2012 and 2017. However, because of the large number of NAFLD patients and that only a minority of patients would eventually develop liver-related morbidity and mortality, non-invasive tests are preferred as initial assessment.

\footnotetext{
Abbreviations:

ALT, alanine aminotransferase; AUROC, area under the receiver-operating characteristics curve; BMI, body mass index; CACLD, compensated advanced chronic liver disease; CAP, controlled attenuation parameter; $\mathrm{Cl}$, confidence interval; EGD, esophagogastroduodenoscopy; EV, esophageal varices; ICC, intraclass correlation coefficient; IQR-M, interquartile range-to-median ratio; LSM, liver stiffness measurement; MRE, magnetic resonance elastography; MRI-PDFF, magnetic resonance imaging proton density fat fraction; NAFL, nonalcoholic fatty liver; NAFLD, nonalcoholic fatty liver disease; NASH, nonalcoholic steatohepatitis
}

\section{Corresponding author : Vincent Wai-Sun Wong}

Department of Medicine and Therapeutics, Prince of Wales Hospital, 30 32 Ngan Shing Street, Shatin, Hong Kong

Tel: +852 35051205, Fax: +852 26373852

E-mail:wongv@cuhk.edu.hk

https://orcid.org/0000-0003-2215-9410 
Among the available non-invasive tests, vibration-controlled transient elastography (FibroScan ${ }^{\circledR}$, Echosens, Paris, France) is commonly used by hepatologists in Europe and Asia. ${ }^{4}$ In 2013, the machine was approved by the United States Food and Drug Administration and has rapidly been introduced to different American centers since then. The latest models of transient elastography have different probes $(S, M$, and $\mathrm{XL})$ to cater for patients with different body build. They also measure both the controlled attenuation parameter (CAP) for hepatic steatosis and liver stiffness for liver fibrosis. In this article, we review the literature on the performance of CAP and liver stiffness measurement (LSM). We discuss the use of $\mathrm{M}$ and $\mathrm{XL}$ probes, and the reliability criteria of transient elastography examination. Because some but not all studies suggest that hepatic steatosis may confound LSM, we specifically review this issue and highlight other confounding factors.

\section{LIVER HISTOLOGY}

NAFLD is an umbrella term covering the spectrum of disease ranging from nonalcoholic fatty liver (NAFL) to NASH. ${ }^{5}$ NAFL is defined as the presence of hepatic steatosis with no hepatocellular injury. ${ }^{6}$ NASH is defined as the presence of hepatic steatosis and inflammation with hepatocyte injury with or without fibrosis, which is the more progressive form of NAFLD. ${ }^{7}$ A subset of patients with NAFLD develop progressive fibrosis, with risk of progression to cirrhosis and hepatocellular carcinoma. ${ }^{8}$ Key histological features of NAFLD include steatosis, lobular inflammation, portal inflammation, hepatocyte ballooning and fibrosis. ${ }^{9}$ Among the histological features, fibrosis stage has the strongest prognostic significance. The NASH Clinical Research Network system adopts a 5 -point fibrosis staging system (0, no fibrosis; 1 , perisinusoidal or portal/periportal only; 2, perisinusoidal and periportal; 3 , bridging fibrosis; 4, cirrhosis). ${ }^{10}$ Fibrosis stage is the most important histological predictor of all-cause and liver related mortality. ${ }^{11,12}$ A systematic review and meta-analysis reported that the risk of liver-related mortality increased with fibrosis stage. ${ }^{13} \mathrm{~A}$ number of issues limit the wide application of liver biopsy for the assessment of NAFLD. Firstly, liver biopsy is an invasive procedure associated with pain and discomfort, and even a small risk of complications such as bleeding. ${ }^{4}$ Secondly, liver biopsy is not widely acceptable for its costs and availability and it is impractical to do it repeatedly to assess disease progression. ${ }^{14}$ Thirdly, sampling variability is common because a biopsy specimen only represents only $1 / 50,000$ of the liver volume, which easily causes mis- diagnosis. ${ }^{15}$ Finally, interobserver variation also heavily influences the assessment of NASH, especially for necroinflammation activity..$^{10}$ Therefore, liver biopsy is not a true gold standard for the evaluation of NAFLD. There is an urgent need to find non-invasive ways to assess patients with NAFLD.

\section{CONTROLLED ATTENUATION PARAMETER (CAP)}

\section{Mechanism}

The latest model of transient elastography measures CAP and liver stiffness simultaneously. ${ }^{16}$ The former reflects the degree of hepatic steatosis. The typical features of fatty liver on abdominal ultrasonography include bright liver echotexture, deep attenuation of ultrasound signal and vascular blunting. ${ }^{5}$ The latter two features are because of the faster attenuation of ultrasound wave amplitude in a steatotic liver. CAP takes advantage of this physical property and estimates the ultrasound attenuation at the central frequency of transient elastography, while assuming a homogeneous fat distribution and an adequate penetration. ${ }^{17}$

\section{Performance}

Although abdominal ultrasonography is often the first-line investigation for the diagnosis of NAFLD, it is operator-dependent and is insensitive to mild hepatic steatosis. ${ }^{4}$ Typically, hepatic steatosis has to involve more than $30 \%$ of hepatocytes before ultrasonography can reliably detect fatty liver. ${ }^{18}$ Table 1 summarizes studies comparing the performance of CAP against liver histology for the detection of various steatosis grades. ${ }^{19-31}$ Overall, the areas under receiver-operating characteristics curves (AUROC) are $81-84 \%$ for $\geq S 1$ (steatosis in at least $5-10 \%$ of hepatocytes), $85-88 \%$ for $\geq \mathrm{S2}(33 \%)$, and $86-91 \%$ for $\mathrm{S3}(66 \%)$ steatosis. The reported sensitivities for $\geq \mathrm{S1}, \geq \mathrm{S} 2$ and $\mathrm{S} 3$ are $60-75 \%, 69-84 \%$ and $77-96 \%$, respectively. The corresponding specificities are $76-90 \%, 75-88 \%$ and $72-82 \%$, respectively. A patient-level meta-analysis of nineteen studies involving 2,735 patients shows similar findings, with a pooled sensitivities and specificities of $69 \%$ and $82 \%$ for $\geq \$ 1,77 \%$ and $81 \%$ for $\geq S 2$, and $88 \%$ and $78 \%$ for $53 .^{32}$ The optimal cutoffs of CAP are $248 \mathrm{~dB} / \mathrm{m}$ for $\mathrm{S1}$, $268 \mathrm{~dB} / \mathrm{m}$ for $\mathrm{S} 2$ and $280 \mathrm{~dB} / \mathrm{m}$ for $\mathrm{S} 3$. It should be noted that some studies used patients with other liver diseases as controls without hepatic steatosis. Since such patients underwent liver bi- 
Table 1. Performance of controlled attenuation parameter in studies using histology as reference

\begin{tabular}{|c|c|c|c|c|c|c|c|}
\hline Study (year) & $\mathrm{N}$ & Target & $\begin{array}{l}\text { Cutoff } \\
(\mathrm{dB} / \mathrm{m})\end{array}$ & Sn (\%) & $\mathrm{Sp}(\%)$ & PPV (\%) & NPV (\%) \\
\hline \multirow[t]{3}{*}{ Sasso et al. ${ }^{19}$ (2012) } & \multirow[t]{3}{*}{$615 \mathrm{CHC}$ patients } & S1-S3 (S1 11-33\% steatosis) & 222 & 43 & 93 & 71 & 79 \\
\hline & & S2-S3 & 233 & 26 & 99 & 77 & 90 \\
\hline & & S3 & 290 & 78 & 93 & 15 & 100 \\
\hline \multirow{3}{*}{$\begin{array}{l}\text { de Lédinghen et al. }{ }^{20} \\
\text { (2012) }\end{array}$} & \multirow{3}{*}{$\begin{array}{l}112 \text { patients } \\
\text { ALD: 6; NAFLD: 28; CHC: 40; } \\
\text { miscellaneous: } 38\end{array}$} & S1-S3 (S1 11-33\% steatosis) & 263 & 71 & 93 & 81 & 74 \\
\hline & & S2-S3 & 311 & 57 & 94 & 81 & 83 \\
\hline & & S3 & 318 & 87 & 91 & 65 & 97 \\
\hline \multirow[t]{3}{*}{ Myers et al. ${ }^{17}$ (2012) } & \multirow{3}{*}{$\begin{array}{l}153 \text { patients } \\
\text { Viral hepatitis: 67; NAFLD: } \\
\text { 72; other: } 14\end{array}$} & S1-S3 (S1 5-33\% steatosis) & 289 & 68 & 88 & 94 & 49 \\
\hline & & $\mathrm{S} 2-\mathrm{S} 3$ & 288 & 85 & 62 & 55 & 88 \\
\hline & & S3 & 283 & 94 & 47 & 17 & 98 \\
\hline \multirow[t]{3}{*}{ Chan et al..$^{21}(2014)$} & \multirow{3}{*}{$\begin{array}{l}238 \text { patients } \\
\text { CHB: } 133 ; \text { NAFLD: 93; } \\
\text { other: } 12\end{array}$} & S1-S3 (S1 5-33\% steatosis) & 263 & 92 & 94 & 96 & 88 \\
\hline & & $\mathrm{S} 2-\mathrm{S} 3$ & 281 & 89 & 74 & 70 & 91 \\
\hline & & S3 & 283 & 93 & 54 & 16 & 99 \\
\hline \multirow[t]{3}{*}{ Shen et al..$^{22}$ (2014) } & \multirow{3}{*}{$\begin{array}{l}152 \text { patients } \\
\text { CHB: 100; NAFLD: } 52\end{array}$} & S1-S3 (S1 5-33\% steatosis) & 253 & 89 & 83 & 88 & 84 \\
\hline & & $\mathrm{S} 2-\mathrm{S} 3$ & 285 & 93 & 83 & 70 & 97 \\
\hline & & S3 & 310 & 92 & 79 & 29 & 99 \\
\hline \multirow[t]{3}{*}{ Chon et al..$^{23}$ (2014) } & \multirow[t]{3}{*}{135 CLD patients } & S1-S3 (S1 5-33\% steatosis) & 250 & 73 & 95 & 97 & 62 \\
\hline & & $\mathrm{S} 2-\mathrm{S3}$ & 299 & 82 & 86 & 67 & 94 \\
\hline & & S3 & 327 & 78 & 84 & 26 & 98 \\
\hline \multirow[t]{3}{*}{ Mi et al. ${ }^{24}(2015)$} & \multirow[t]{3}{*}{340 CHB patients } & S1-S3 (S1 5-33\% steatosis) & 224 & 76 & 75 & 68 & 80 \\
\hline & & $\mathrm{S} 2-\mathrm{S} 3$ & 236 & 92 & 70 & 21 & 99 \\
\hline & & S3 & 285 & 1 & 93 & 23 & 1 \\
\hline \multirow[t]{3}{*}{ Imajo et al. ${ }^{25}$ (2016) } & \multirow[t]{3}{*}{127 NAFLD patients } & S1-S3 (S1 5-33\% steatosis) & 236 & 82 & 91 & 99 & 67 \\
\hline & & S2-S3 & 270 & 78 & 81 & 73 & 76 \\
\hline & & S3 & 302 & 64 & 74 & 76 & 94 \\
\hline \multirow{3}{*}{$\begin{array}{l}\text { de Lédinghen et al. }{ }^{26} \\
\text { (2016) }\end{array}$} & \multirow[t]{3}{*}{261 NAFLD patients } & S1-S3 (S1 5-33\% steatosis) & - & - & - & - & - \\
\hline & & S2-S3 & 310 & 79 & 71 & 86 & 59 \\
\hline & & S3 & 311 & 87 & 47 & 43 & 88 \\
\hline \multirow[t]{3}{*}{ Park et al. ${ }^{27}$ (2017) } & \multirow[t]{3}{*}{104 NAFLD patients } & S1-S3 (S1 5-33\% steatosis) & 261 & 72 & 86 & 98 & 23 \\
\hline & & S2-S3 & 305 & 63 & 69 & 56 & 75 \\
\hline & & S3 & 312 & 64 & 70 & 26 & 92 \\
\hline \multirow[t]{3}{*}{ Chan et al. ${ }^{28}$ (2018) } & \multirow[t]{3}{*}{180 CLD patients } & S1-S3 (S1 5-33\% steatosis) & 253 & 93 & 71 & 97 & 50 \\
\hline & & S2-S3 & 294 & 85 & 59 & 77 & 70 \\
\hline & & S3 & 294 & 88 & 36 & 24 & 93 \\
\hline \multirow[t]{3}{*}{ Garg et al. ${ }^{29}$ (2018) } & \multirow[t]{3}{*}{124 NAFLD patients } & S1-S3 (S1 5-33\% steatosis) & 323 & 59 & 83 & 97 & 15 \\
\hline & & S2-S3 & 336 & 74 & 76 & 57 & 87 \\
\hline & & S3 & 357 & 100 & 78 & 20 & 1 \\
\hline Siddiqui et al. ${ }^{30}$ (2019) & 393 NAFLD patients & S1-S3 (\$1 5-33\% steatosis) & 285 & 80 & 77 & 99 & 16 \\
\hline & & $\mathrm{S} 2-\mathrm{S} 3$ & 311 & 77 & 57 & 70 & 66 \\
\hline & & S3 & 306 & 80 & 40 & 32 & 85 \\
\hline Eddowes et al. ${ }^{31}$ (2019) & 415 NAFLD patients & S1-S3 (S1 5-33\% steatosis) & 302 & 80 & 83 & 97 & 37 \\
\hline & & S2-S3 & 331 & 70 & 76 & 84 & 58 \\
\hline & & S3 & 337 & 72 & 63 & 52 & 80 \\
\hline
\end{tabular}

Steatosis was graded as the percentage of hepatocytes with fat: SO $\leq 5 \%$ or $10 \%, S 1: 5 \%-33 \%$ or $11-33 \%, S 2: 34-66 \%, S 3 \geq 67 \%$.

Sn, sensitivity; Sp, specificity; PPV, positive predictive value; NPV, negative predictive value; CHC, chronic hepatitis C; ALD, alcoholic liver disease; NAFLD, nonalcoholic fatty liver disease; CHB, chronic hepatitis B; CLD, chronic liver disease. 
opsies with other indications, they do not represent a healthy population of subjects. This may have affected the derivation of optimal cutoffs and the evaluation of test performance. Furthermore, the test evaluation is affected by patient composition. Studies based on more obese NAFLD cohorts in Europe and North America usually recommend higher cutoff values for each steatosis grade. ${ }^{30,31}$

Magnetic resonance imaging (MRI) such as estimated proton density fat fraction (MRI-PDFF) and proton-magnetic resonance spectroscopy is also a leading non-invasive test for steatosis quantification with high sensitivity and specificity. ${ }^{33} \mathrm{MRI}$ is not affected by obesity and has higher success rate of examination than transient elastography. ${ }^{27}$ Recently, Caussy and colleagues compared CAP and MRI-PDFF in 119 individuals with and without NAFLD. ${ }^{34}$ The AUROC of CAP to detect MRI-PDFF $\geq 5 \%$ was reasonable at 0.80 , whereas that for MRI-PDFF $\geq 10 \%$ was 0.87 . The optimal CAP cutoffs for these two MRI-PDFF thresholds were 288 $\mathrm{dB} / \mathrm{m}$ and $306 \mathrm{~dB} / \mathrm{m}$.

While most of the validation studies are cross-sectional in nature, it is important to remember that patients often require serial examinations for disease progression and treatment response. In that regard, MRI-PDFF is precise and can detect small changes in hepatic steatosis over time. ${ }^{35}$ In contrast, although CAP is reproducible on repeated testing, ${ }^{36}$ further longitudinal studies should clarify its performance as a monitoring tool.

\section{Clinical applications}

Although MRI-PDFF has superior performance to CAP, the former is limited by cost and availability. ${ }^{34}$ In clinical practice, CAP is a reasonable test for the diagnosis of NAFLD, especially as abdominal ultrasonography may be falsely negative when $<30 \%$ of hepatocytes are steatotic. ${ }^{37}$ Studies have shown that CAP has strong association with metabolic syndrome, body mass index (BMI), and chronic hepatitis C. ${ }^{19,32,38}$ CAP is therefore an important and non-invasive method for screening fatty liver in the general population or high-risk population such as patients with type 2 diabetes, obesity and chronic liver diseases (Table 2). ${ }^{39,40}$

\section{LIVER STIFFNESS MEASUREMENT (LSM)}

\section{Mechanism}

During LSM by transient elastography, vibrations of mild amplitude and low frequency $(50 \mathrm{~Hz})$ are transmitted by the transducer, inducing an elastic shear wave that propagates through the underlying tissues. ${ }^{41}$ Pulse-echo ultrasound acquisition is used to follow the propagation of the shear wave and to measure its velocity, which is directly related to tissue stiffness: the stiffer the tissue, the faster the shear wave propagates. ${ }^{16}$ LSM values range from 1.5 to $75 \mathrm{kPa}$; lower values indicate a more elastic liver. ${ }^{42}$ Transient elastography measures liver stiffness in a volume at least 100 times bigger than a biopsy sample, and is therefore far more representative and reliable. ${ }^{43}$

\section{Performance}

Transient elastography is painless, rapid and easy to perform at the bedside or in the clinic. It allows rapid and non-invasive estimation of hepatic fibrosis in patients with various chronic liver diseases including chronic hepatitis $\mathrm{C}_{1}^{44}$ chronic hepatitis $\mathrm{B}_{1}^{45}$ and NAFLD. ${ }^{46}$ Table 3 shows studies on the performance of LSM in NAFLD patients compared with liver biopsy. ${ }^{25,27,29-31,47-51}$ Overall, the AUROC of LSM for stages F1, F2, F3, and F4 were $0.82,0.85$, 0.94 , and 0.96 , respectively. For $\mathrm{F} 2-4$ fibrosis, the LSM cut-off values range from 6.2 to $11 \mathrm{kPa}$, with $62-90 \%$ sensitivity and $74-100 \%$ specificity. For F3-4 fibrosis, the LSM cut-off values range from 8 to $12 \mathrm{kPa}$, with $84-100 \%$ sensitivity and $83-97 \%$ specificity. For F4, the LSM cut-off values range from 9.5 to

Table 2. Clinical applications of transient elastography

\begin{tabular}{ll}
\hline $\begin{array}{l}\text { Controlled attenuation } \\
\text { parameter }\end{array}$ & - Diagnosis of fatty liver \\
& - Screening for fatty liver in the general population of high-risk individuals (e.g., type 2 diabetes and obesity) \\
& - Monitor changes in liver fat (need more data) \\
Liver stiffness measurement & - Estimate severity of liver fibrosis in NAFLD patients \\
& - Selecting patients for clinical trials or pharmacological treatment \\
& - Screen for liver fibrosis in the general population of high-risk individuals (e.g., type 2 diabetes and obesity) \\
& - Predict varices needing treatment, hepatocellular carcinoma and liver-related death \\
& - Monitor changes in liver fibrosis (need more data)
\end{tabular}

NAFLD, nonalcoholic fatty liver disease. 
Table 3. Performance of liver stiffness measurement in NAFLD studies using histology as reference

\begin{tabular}{|c|c|c|c|c|c|c|c|c|}
\hline Study (year) & $\mathbf{N}$ & Probe & Target & Cutoff (kPa) & Sn (\%) & $\mathrm{Sp}(\%)$ & PPV (\%) & NPV (\%) \\
\hline \multirow[t]{4}{*}{ Yoneda et al..$^{99}$ (2007) } & 67 & M & F1-F4 & 5.6 & 83 & 81 & 94 & 59 \\
\hline & & & $\mathrm{F} 2-\mathrm{F} 4$ & 6.7 & 82 & 91 & 90 & 84 \\
\hline & & & F3-F4 & 8.0 & 88 & 84 & 64 & 96 \\
\hline & & & F4 & 17.0 & 100 & 98 & 83 & 100 \\
\hline \multirow[t]{4}{*}{ Yoneda et al. ${ }^{46}$ (2008) } & 97 & M & F1-F4 & 5.9 & 86 & 89 & 97 & 59 \\
\hline & & & $\mathrm{F} 2-\mathrm{F} 4$ & 6.7 & 88 & 74 & 79 & 85 \\
\hline & & & F3-F4 & 9.8 & 85 & 81 & 64 & 93 \\
\hline & & & $\mathrm{F} 4$ & 17.5 & 100 & 97 & 75 & 100 \\
\hline \multirow[t]{3}{*}{ Wong et al. ${ }^{47}$ (2010) } & 246 & M & F2-F4 & 7.0 & 79 & 76 & 70 & 84 \\
\hline & & & F3-F4 & 8.7 & 84 & 83 & 60 & 95 \\
\hline & & & $\mathrm{F} 4$ & 10.3 & 92 & 88 & 46 & 99 \\
\hline \multirow[t]{3}{*}{ Gaia et al. ${ }^{48}$ (2011) } & 72 & M & $\mathrm{F} 1-\mathrm{F} 4$ & 5.5 & 84 & 57 & 80 & 62 \\
\hline & & & F2-F4 & 7.0 & 76 & 80 & 75 & 78 \\
\hline & & & F3-F4 & 8.0 & 65 & 80 & 48 & 86 \\
\hline \multirow[t]{6}{*}{ Wong et al. ${ }^{49}$ (2012) } & 193 & M & F2-F4 & 5.8 & 94 & 42 & 54 & 90 \\
\hline & & & F3-F4 & 7.9 & 88 & 68 & 51 & 94 \\
\hline & & & F4 & 10.3 & 81 & 83 & 35 & 98 \\
\hline & & $X L$ & $\mathrm{~F} 2-\mathrm{F} 4$ & 4.8 & 92 & 37 & 54 & 84 \\
\hline & & & F3-F4 & 5.7 & 91 & 54 & 45 & 93 \\
\hline & & & $\mathrm{F} 4$ & 7.2 & 92 & 70 & 31 & 98 \\
\hline \multirow[t]{4}{*}{ Kumar et al. ${ }^{50}$ (2013) } & 120 & M & $\mathrm{F} 1-\mathrm{F} 4$ & 6.1 & 78 & 68 & 87 & 53 \\
\hline & & & F2-F4 & 7.0 & 77 & 78 & 75 & 81 \\
\hline & & & F3-F4 & 9.0 & 85 & 88 & 68 & 95 \\
\hline & & & $\mathrm{F} 4$ & 11.8 & 90 & 88 & 41 & 98 \\
\hline \multirow[t]{4}{*}{ Imajo et al. ${ }^{25}$ (2016) } & 142 & M & F1-F4 & 7.0 & 62 & 100 & 100 & 87 \\
\hline & & & F2-F4 & 11.0 & 65 & 89 & 88 & 66 \\
\hline & & & F3-F4 & 11.4 & 86 & 84 & 75 & 92 \\
\hline & & & $\mathrm{F} 4$ & 14.0 & 100 & 76 & 73 & 100 \\
\hline \multirow[t]{4}{*}{ Lee et al. ${ }^{51}$ (2016) } & 183 & M & F1-F4 & 6.7 & 66 & 85 & 88 & 63 \\
\hline & & & F2-F4 & 8.0 & 83 & 85 & 64 & 94 \\
\hline & & & F3-F4 & 9.0 & 96 & 86 & 55 & 99 \\
\hline & & & $\mathrm{F} 4$ & 11.0 & 100 & 90 & 45 & 100 \\
\hline \multirow[t]{4}{*}{ Park et al. ${ }^{27}$ (2017) } & 104 & M & $\mathrm{F} 1-\mathrm{F} 4$ & 6.1 & 67 & 65 & 69 & 62 \\
\hline & & & F2-F4 & 6.9 & 79 & 85 & 70 & 90 \\
\hline & & & F3-F4 & 7.3 & 78 & 78 & 45 & 94 \\
\hline & & & $\mathrm{F} 4$ & 6.9 & 63 & 66 & 15 & 95 \\
\hline \multirow[t]{3}{*}{ Garg et al.. (2018) } & 124 & $X L$ & $\mathrm{~F} 1-\mathrm{F} 4$ & 6.0 & 80 & 56 & 87 & 43 \\
\hline & & & F2-F4 & 7.3 & 70 & 59 & 53 & 76 \\
\hline & & & F3-F4 & 12.5 & 64 & 88 & 47 & 93 \\
\hline \multirow[t]{4}{*}{ Siddiqui et al..$^{30}$ (2019) } & 393 & M & F1-F4 & 8.6 & 53 & 87 & 93 & 37 \\
\hline & & & $\mathrm{F} 2-\mathrm{F} 4$ & 8.6 & 66 & 80 & 78 & 70 \\
\hline & & & F3-F4 & 8.6 & 80 & 74 & 59 & 89 \\
\hline & & & F4 & 13.1 & 89 & 86 & 39 & 99 \\
\hline \multirow[t]{3}{*}{ Eddowes et al..$^{31}$ (2019) } & 415 & M: 138 & $\mathrm{~F} 2-\mathrm{F} 4$ & 8.2 & 71 & 70 & 78 & 61 \\
\hline & & $X \mathrm{~L}: 277$ & F3-F4 & 9.7 & 71 & 75 & 63 & 81 \\
\hline & & & F4 & 13.6 & 85 & 79 & 29 & 98 \\
\hline
\end{tabular}

NAFLD, nonalcoholic fatty liver disease; Sn, sensitivity; Sp, specificity; PPV, positive predictive value; NPV, negative predictive value. 
$20 \mathrm{kPa}$, with $90-100 \%$ sensitivity and $75.9-98.4 \%$ specificity.

In a meta-analysis of nine studies, ${ }^{52}$ the estimates for sensitivity were $87 \%$ (95\% confidence interval [CI], 84-90\%), specificity 91\% (95\% Cl, 89-92\%), positive likelihood ratio $11.7(95 \% \mathrm{Cl}$, 7.9-17.1), and negative likelihood ratio $0.14(95 \% \mathrm{Cl}, 0.10-0.20)$. The optimal cutoff varies across studies as it is a tradeoff between sensitivity and specificity and may be influenced by the underlying liver disease.

Magnetic resonance elastography (MRE) is a MRI-based method for quantitatively imaging tissue stiffness. Multiple studies have shown that MRE can be a useful method for the diagnosis of liver fibrosis in patients with NAFLD, even in the early stages. Imajo and colleagues performed a cross-sectional study comparing transient elastography and MRE in 142 Japanese patients with biopsyproven NAFLD. ${ }^{25}$ The AUROC curve in diagnosing liver fibrosis stage 1, 2, 3, and 4 using MRE and transient elastography were 0.80 vs. $0.78,0.89$ vs. $0.82,0.89$ vs. 0.88 , and 0.97 vs. 0.92 , respectively. The reported sensitivities for F1-4, F2-4, F3-4 and F4 fibrosis were $75 \%$ vs. $61.7 \%, 87.3 \%$ vs. $65.2 \%, 74.5 \%$ vs. $85.7 \%$ and $90.9 \%$ vs. $100 \%$, respectively. The corresponding specificities were $85.7 \%$ vs. $100 \%, 85 \%$ vs. $88.7 \%, 86.9 \%$ vs. $83.8 \%$ and $94.5 \%$ vs. $75.9 \%$, respectively. The findings were confirmed in another study with head-to-head comparison of the two techniques in the United States. ${ }^{27}$ The results indicate that MRE has higher diagnostic accuracy in the assessment of liver fibrosis than transient elastography, though the absolute difference is marginal.

LSM by transient elastography is highly reproducible. In the study by Fraquelli and colleagues, ${ }^{53} 800$ transient elastography examinations were performed in 200 patients with chronic liver diseases and the overall interobserver agreement intraclass correlation coefficient (ICC) was 0.98 (95\% Cl, 0.977 to 0.987). How- ever, increased body mass index $\left(25 \mathrm{~kg} / \mathrm{m}^{2}\right)$, steatosis, and fibrosis stage $<2$ were associated with reduced ICC.

\section{Predicting liver related complications}

Transient elastography not only allows early identification of patients with fibrosis and cirrhosis but also plays an important part in predicting complications of compensated advanced chronic liver disease (CACLD), such as gastroesophageal varices, hepatocellular carcinoma and liver-related deaths. Variceal hemorrhage is a common and severe complication of CACLD. Screening for the presence of esophageal varices (EV) with esophagogastroduodenoscopy (EGD; the gold standard) in cirrhotic patients is recommended by current guidelines, but EGD is costly and inconvenient. Many studies have shown that transient elastography has potential value in the prediction of $\mathrm{EV}^{54-56}$ The Baveno $\mathrm{VI}$ consensus states that patients with $\mathrm{LSM}<20-25 \mathrm{kPa}$ and a normal platelet count of $\geq 150 \times 10^{9} / \mathrm{L}$ are unlikely to harbor varices needing treatment and may be spared from endoscopy. ${ }^{57}$ This notion has since been validated in different settings. In a large multicenter cohort of patients with NASH-related cirrhosis, Petta and colleagues demonstrated the role of probe-specific LSM and platelet count to detect varices needing treatment. ${ }^{58}$ The study also suggests the possibility of loosening the criteria (LSM $30 \mathrm{kPa}$ for M probe and $25 \mathrm{kPa}$ for $\mathrm{XL}$ probe; platelet count $\left.110 \times 10^{9} / \mathrm{L}\right)$ to reduce the number of patients requiring endoscopy further without jeopardizing the false-negative rate (Fig. 1).

In addition to $E V$, one of the most important complications of liver fibrosis progression is the development of hepatocellular carcinoma. Several studies have proposed that transient elastography can be used to assess the risks of development of hepatocellular

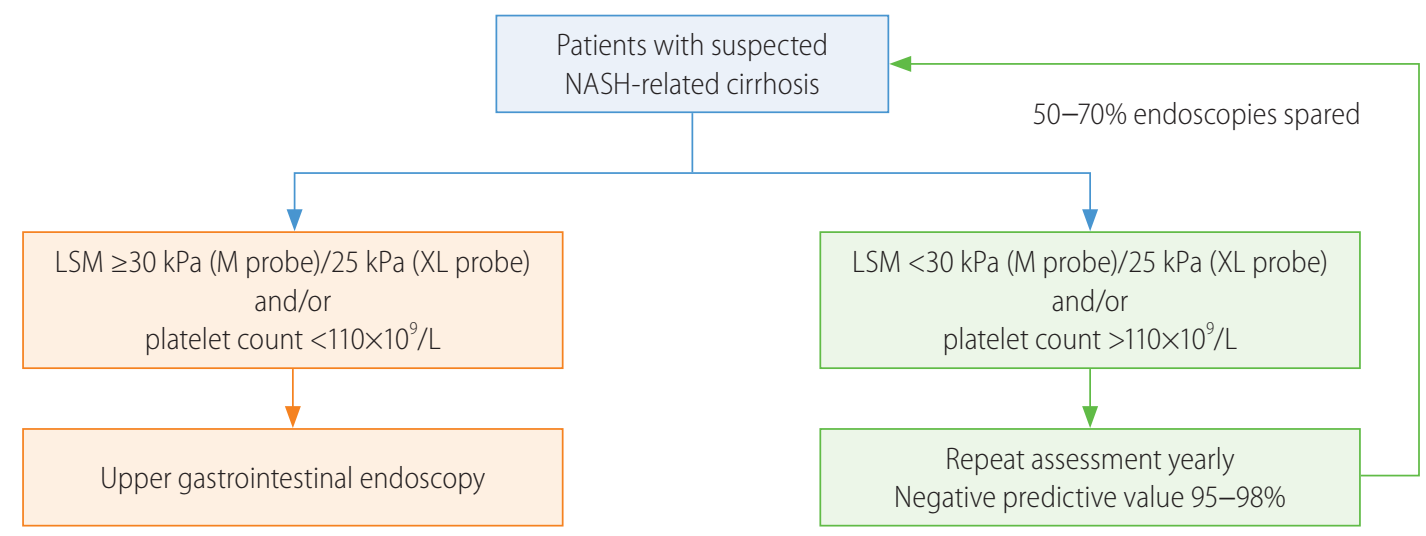

Figure 1. Modified Baveno VI's criteria to select NAFLD patients for endoscopic screening for varices. NASH, nonalcoholic steatohepatitis; LSM, liver stiffness measurement. ${ }^{58}$ 
carcinoma, based on the significant correlation between the risk of hepatocellular carcinoma development and the degree of liver fibrosis. ${ }^{59-61}$ A recent systematic review and meta-analysis performed by Singh and colleagues also support these findings. ${ }^{62}$ Furthermore, recent studies have shown an association between LSM and survival. Among 2,052 patients with chronic liver diseases, Pang and colleagues reported that LSM by transient elastography had excellent accuracy in predicting the risk of death in patients with chronic liver diseases. ${ }^{63}$ On the other hand, CAP does not appear to predict liver-related outcomes. ${ }^{64}$ This is in line with liver biopsy studies showing that steatosis is not as important a prognostic marker as the other histological features. ${ }^{65}$

\section{Clinical applications}

Above all, transient elastography can be performed to estimate severity of liver fibrosis in NAFLD patients at both the primary care and specialist settings. A recent meta-analysis included nine studies consisting of 1,047 NAFLD patients suggests that transient elastography is excellent in diagnosing F3-4 (85\% sensitivity, $82 \%$ specificity) and F4 fibrosis ( $92 \%$ sensitivity, $92 \%$ specificity) and has moderate accuracy for $\mathrm{F} 2-4$ fibrosis (79\% sensitivity, $75 \%$ specificity). ${ }^{66}$ Secondly, transient elastography can contribute to select patients for clinical trials or pharmacological treatment. transient elastography not only has good accuracy and high reproducibility of liver fibrosis, but also has the advantage of being quick, non-invasive, easy to learn and well tolerated by patients, which makes it widely utilize in scientific research. ${ }^{67,68}$ Thirdly, transient elastography can be used to screen for liver fibrosis in the general population of high-risk individuals (e.g., type 2 diabetes and obesity). The overall impact of obesity, type 2 diabetes and other metabolic risk factors on liver fibrosis are greatly underestimated by current practice. In a population-based study among individuals over 45 years using transient elastography showed that both $\mathrm{BMI}>30 \mathrm{~kg} / \mathrm{m}^{2}$ and type 2 diabetes were significantly associated with liver stiffness $\geq 8 \mathrm{kPa} .{ }^{69}$ In another study of 1,918 patients with type 2 diabetes, $72.8 \%$ had fatty liver and $17.7 \%$ had high liver stiffness suggestive of advanced fibrosis, highlighting the importance of case finding or even screening in this high risk population. ${ }^{39}$ In patients with NASH-related cirrhosis, LSM is a useful tool to predict varices, hepatocellular carcinoma and liverrelated death. The Baveno VI criteria and its modifications are good starting points to select patients for endoscopic screening. ${ }^{70}$ Last but not least, some studies indicate that transient elastography can be used to monitor fibrosis changes after treatment, though this should be confirmed by further studies using paired liver biopsies. ${ }^{71,72}$

\section{AND XL PROBES}

One of the biggest challenge of transient elastography examination is the lower success rate in obese patients. ${ }^{73}$ This is particularly relevant for NAFLD because of its close association with obesity. ${ }^{74}$ To cater for this limitation, the manufacturer of transient elastography has produced different probes to cater for patients with different body build. While the M probe is for average adults, the $S$ probe is for children and adolescents and the $\mathrm{XL}$ probe is for obese patients. By using a lower frequency $(2.5 \mathrm{MHz}$ instead of $3.5 \mathrm{MHz}$ for the $\mathrm{M}$ probe), the $\mathrm{XL}$ probe measures $\mathrm{CAP}$ and liver stiffness at a greater depth (35-75 vs. $25-65 \mathrm{~mm}) .^{75}$ Even in the obese population, the $\mathrm{XL}$ probe allows successful measurements in the majority of cases. ${ }^{49,76,77}$

Because ultrasound-based transient elastography measures the Young's modulus and is expected to be affected by ultrasound frequency ${ }_{1}{ }^{41}$ prospective studies indeed confirmed that the XL probe would yield a lower liver stiffness value than the M probe when applied on the same patient. ${ }^{49,76}$ Nonetheless, since high body mass index also leads to higher liver stiffness values (see section on confounding factors), the effects of obesity and XL probe on LSM tend to cancel each other. When we applied the $M$ probe in patients with body mass index $<30 \mathrm{~kg} / \mathrm{m}^{2}$ and $\mathrm{XL}$ probe in those $\geq 30 \mathrm{~kg} / \mathrm{m}^{2}$, the median liver stiffness values by both probes were nearly identical at each fibrosis stage, suggesting that one may adopt the same interpretation when the right probe is used for the right patient (Fig. 2). ${ }^{78}$ In our hands, the same CAP cutoffs can also be used for the two probes with similar accuracy. ${ }^{28}$ The latest model of transient elastography has an automated probe selection tool that recommends the use of the $\mathrm{M}$ or $\mathrm{XL}$ probes based on the skin-to-liver capsule distance. When the probe selection tool is followed, again it does not appear that cutoff adjustments are required for the two probes. ${ }^{31}$

\section{RELIABILITY CRITERIA}

During a transient elastography examination, an operator typically obtains ten measurements. The median values of CAP and liver stiffness reflect the degree of hepatic steatosis and fibrosis, respectively, whereas the interquartile range (IQR) of the ten mea- 


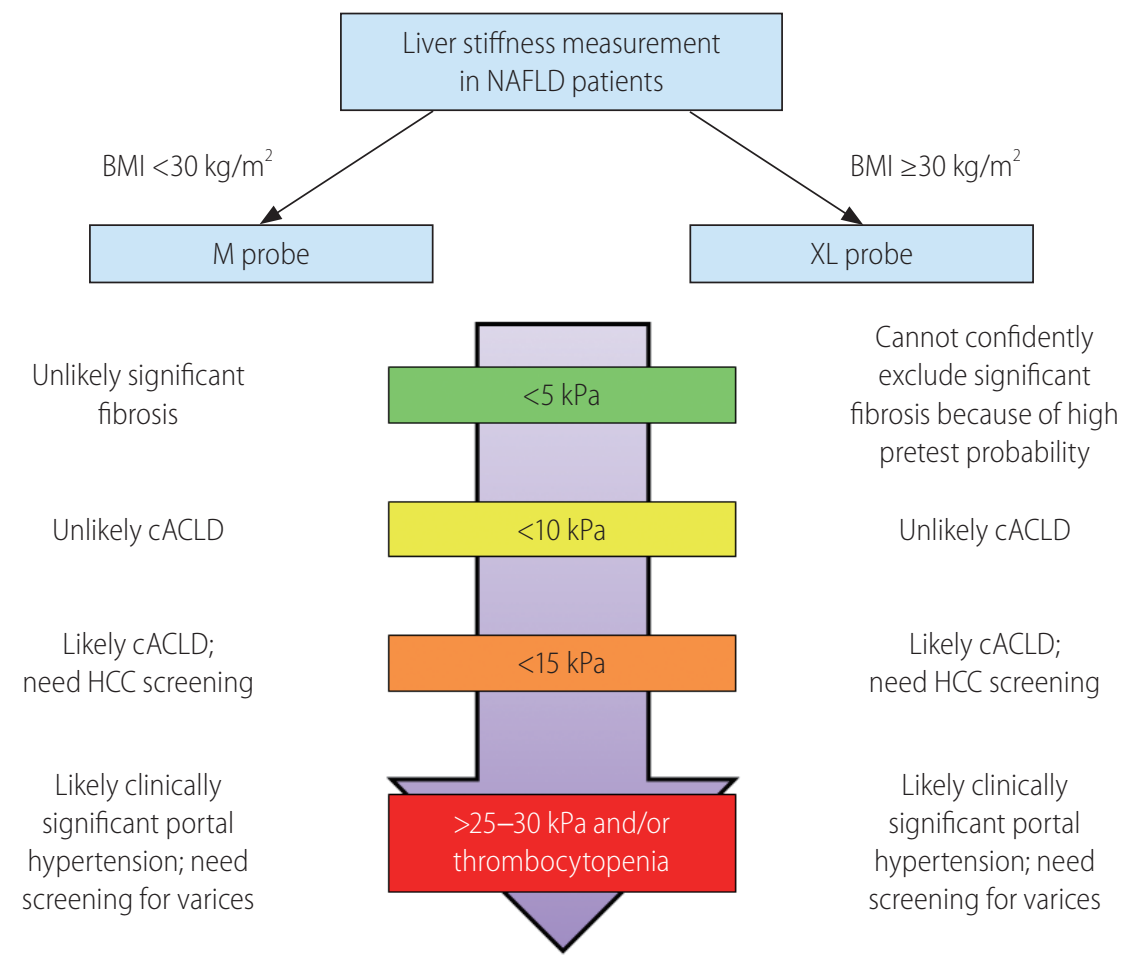

Figure 2. Unified interpretation of liver stiffness measurement by $M$ and XL probes in NAFLD patients. Reproduced from Wong et al. ${ }^{78}$ with permission from BMJ Publishing Group Ltd. NAFLD, nonalcoholic fatty liver disease; BMI, body mass index; CACLD, compensated advanced chronic liver disease; HCC, hepatocellular carcinoma.

surements represents the variability of measurements. Highly variable measurements suggest a difficult examination, suboptimal technique or heterogeneous pathology in the liver parenchyma. According to the original manufacturer recommendations, a reliable LSM is defined as obtaining ten valid measurements, a success rate (number of valid acquisitions divided by the number of attempts) $>60 \%$, and an interquartile range-to-median ratio (IQR/M) of $\leq 0.3$. However, subsequent studies have not found success rate to be a determinant of reliable examination. ${ }^{47,79}$

In a study of 1,165 French patients with chronic liver disease (798 had chronic hepatitis C), Boursier and colleagues proposed new reliability criteria based on both IQR/M and the median liver stiffness values. ${ }^{80}$ In essence, poorly reliable LSM is defined as IQR/M $>0.30$ and liver stiffness $\geq 7.1 \mathrm{kPa}$ for $\mathrm{F} 2-3$ fibrosis and $\geq 12.5 \mathrm{kPa}$ for F4 fibrosis. Because LSM has a high negative predictive value but a modest positive predictive value ${ }^{81}$ it is reasonable to consider a patient with a liver stiffness of $7.1 \mathrm{kPa}$ or below as not having significant fibrosis, regardless of the other quality indicators. This approach also has the advantage of reducing the proportion of patients classified as having unreliable examinations.
In a study of 754 patients with chronic liver disease and liver histology (349 had NAFLD), our group showed that an absolute CAP IQR of $>40 \mathrm{~dB} / \mathrm{m}$ with $M$ probe measurement was associated with less reliable diagnosis of hepatic steatosis. ${ }^{82}$ The finding was confirmed by another study using MRI-PDFF as the reference standard, ${ }^{34}$ but not in another biopsy-based multicenter United Kingdom study. ${ }^{31}$ Nevertheless, the latter study only included patients with suspected NAFLD, with only 47 having grade 0 steatosis. That cohort is thus not well suited to determine the reliability criteria for the diagnosis of fatty liver.

\section{CONFOUNDING FACTORS}

Well-studied confounding factors for LSM leading to false-positive diagnosis of advanced fibrosis include hepatic congestion, ${ }^{83,84}$ biliary obstruction, ${ }^{85}$ amyloidosis, ${ }^{86}$ and benign and malignant liver lesions. ${ }^{87,88}$ Probably because of increased portal blood flow, liver stiffness increases after meals by $1-5 \mathrm{kPa}{ }^{89}$ The liver stiffness typically peaks at 20 to 40 minutes but may still be increased by 180 minutes. 
Acute viral hepatitis and acute exacerbation of chronic viral hepatitis also increase liver stiffness dramatically. ${ }^{90,91}$ In fact, patients with chronic hepatitis B and serum alanine aminotransferase (ALT) elevation to one to five times the upper limit of normal also have higher liver stiffness than those with normal ALT. ${ }^{45}$ However, ALT elevation does not appear to affect LSM in NAFLD patients. ${ }^{47}$ Two reasons may explain this difference. First, NASH is an insidious disease not usually characterized by episodes of acute exacerbations. In general, the degree of hepatic necroinflammation is less prominent in NASH than viral hepatitis or autoimmune hepatitis. Second, the ALT level correlates poorly with histological necroinflammation in NAFLD patients. ${ }^{92}$

One controversial point is whether severe hepatic steatosis affects liver stiffness. An Italian study showed that severe steatosis increased the false-positive diagnosis of advanced fibrosis by LSM using the M probe in NAFLD patients. ${ }^{93}$ The same applies to patients with high CAP values. ${ }^{42}$ However, it is unclear if the effect is directly due to hepatic steatosis. Other studies have also shown that extreme body mass index is associated with higher liver stiffness. ${ }^{94}$ Recently, our group performed both $\mathrm{M}$ and XL probe measurements on 496 patients with biopsy-proven NAFLD and showed that LSM by the XL probe was not affected by severe steatosis. ${ }^{78}$

Because the above factors represent physical properties of the liver parenchyma, they are expected to affect other kinds of LSMs similarly such as by point-shear wave elastography, 2D-shear wave elastography and magnetic resonance elastography. In contrast, confounding factors for CAP have not been as well studied.

\section{GUIDELINE RECOMMENDATIONS}

The recommendations of this article are largely in keeping with regional guidelines. The American Association for the Study of Liver Diseases guidelines state that transient elastography and MRE are clinically useful tools for identifying advanced fibrosis in patients with NAFLD, whereas simple fibrosis scores such as the NAFLD fibrosis score and Fibrosis- 4 index are clinically useful tools for identifying NAFLD patients with higher likelihood of having bridging fibrosis or cirrhosis. ${ }^{95}$ The joint European Association guidelines on NAFLD recommend biomarkers and scores of fibrosis, as well as transient elastography, as acceptable non-invasive procedures for the identification of cases at low risk of advanced fibrosis or cirrhosis. ${ }^{96}$ They also suggest the use of a combination of biomarkers, scores and transient elastography to monitor fibro- sis progression but highlight that this strategy requires validation. Likewise, the joint European and Latin American guidelines on fibrosis assessment endorse screening of liver fibrosis in high risk populations such as patients with metabolic syndrome or type 2 diabetes. ${ }^{97}$ Non-invasive assessment by serum biomarkers or transient elastography can be used as first line procedure for the identification of patients at low risk of severe fibrosis. They also suggest follow-up assessment by serum biomarkers or transient elastography at a 3-year interval. The Asia-Pacific Working Party of NAFLD guidelines also state that non-invasive serum and physical tests have acceptable accuracies when used to measure the fibrotic burden of NAFLD patients. ${ }^{5}$ Notably, none of the guidelines specify cutoffs for CAP and LSM.

As discussed above, the Baveno $\mathrm{VI}$ consensus statements recommend the use of transient elastography and platelet count to select patients for endoscopic screening for varices. ${ }^{57}$ They also suggest the use of simple cutoffs of define low and high probability of compensated advanced chronic liver disease.

\section{CONCLUSIONS}

The development of transient elastography has allowed simultaneous and reasonably accurate assessment of hepatic steatosis and fibrosis. The technique is thus well suited as a point-of-care diagnostic and assessment tool for NAFLD patients. CAP and LSM has been validated across different regions and patient populations with consistent results. LSM not only reflects the degree of liver fibrosis but also predicts portal hypertension, varices requiring treatment, cirrhotic complications and hepatocellular carcinoma. While obesity used to be a common reason for measurement failure, it is possible to obtain valid measurements in the majority of NAFLD patients when the XL probe is used in obese patients. Importantly, with the automatic probe selection tool, operators can apply the same liver stiffness cutoffs when the $M$ and XL probes are used for the right patients. Nonetheless, whether the same applies to CAP interpretation deserves further studies. Wellvalidated reliability criteria for LSM include the requirement of 10 valid measurements and an IQR/M of less than 0.3. Although two studies suggest the IQR also reflects the reliability of CAP, data are conflicting and need further clarification.

As pharmacological treatment for NASH will likely become available in the near future, it is timely to consider the position of non-invasive tests in different settings. Several prospective studies have illustrated the application of simple fibrosis scores, fibro- 
sis biomarkers and transient elastography to detect significant liver diseases at primary care setting and selective populations. ${ }^{39,98}$ Notably, it may not be feasible to perform transient elastography for all patients with type 2 diabetes and obesity. A stepwise approach using simple fibrosis scores followed by fibrosis biomarkers or LSM will probably be the way to go but needs to be adjusted for the local setting.

\section{Author's contribution}

Xinrong Zhang, Grace Wong and Vincent Wong contributed to the literature review and manuscript preparation.

\section{Conflicts of Interest}

Grace Wong has served as an advisory committee member for Gilead Sciences and Janssen, and a speaker for Abbott, AbbVie, Bristol-Myers Squibb, Echosens, Gilead Sciences, Janssen and Roche. Vincent Wong has served as an advisory committee member or consultant for 3V-BIO, AbbVie, Allergan, Boehringer Ingelheim, Center for Outcomes Research in Liver Diseases, Echosens, Gilead Sciences, Intercept, Janssen, Novartis, Novo Nordisk, Perspectum Diagnostics, Pfizer, TARGET-NASH and Terns, and a speaker for Bristol-Myers Squibb, Echosens, Gilead Sciences, and Merck. Both Grace Wong and Vincent Wong have received unrestricted grants from Gilead Sciences.

\section{REFERENCES}

1. Younossi Z, Tacke F, Arrese M, Chander Sharma B, Mostafa I, Bugianesi $E$, et al. Global perspectives on nonalcoholic fatty liver disease and nonalcoholic steatohepatitis. Hepatology 2019;69:26722682.

2. Younossi Z, Stepanova M, Ong JP, Jacobson IM, Bugianesi E, Duseja A, et al. Nonalcoholic steatohepatitis is the fastest growing cause of hepatocellular carcinoma in liver transplant candidates. Clin Gastroenterol Hepatol 2019;17:748-755.e3.

3. Li J, Zou B, Yeo YH, Feng Y, Xie X, Lee DH, et al. Prevalence, incidence, and outcome of non-alcoholic fatty liver disease in Asia, 1999-2019: a systematic review and meta-analysis. Lancet Gastroenterol Hepatol 2019;4:389-398.

4. Wong VW, Adams LA, de Lédinghen V, Wong GL, Sookoian S. Noninvasive biomarkers in NAFLD and NASH - current progress and future promise. Nat Rev Gastroenterol Hepatol 2018;15:461478.

5. Wong VW, Chan WK, Chitturi S, Chawla Y, Dan YY, Duseja A, et al. Asia-Pacific working party on non-alcoholic fatty liver disease guidelines 2017-part 1: definition, risk factors and assessment. J Gastroenterol Hepatol 2018;33:70-85.

6. Tricò D, Caprio S, Rosaria Umano G, Pierpont B, Nouws J, Galderisi $A$, et al. Metabolic features of nonalcoholic fatty liver (NAFL) in obese adolescents: findings from a multiethnic cohort. Hepatology 2018:68:1376-1390.

7. Castera L. Diagnosis of non-alcoholic fatty liver disease/nonalcoholic steatohepatitis: non-invasive tests are enough. Liver Int 2018;38 Suppl 1:67-70.

8. Byrne CD, Targher G. NAFLD: a multisystem disease. J Hepatol 2014;62(1 Suppl):S47-S64.

9. Bedossa P. Pathology of non-alcoholic fatty liver disease. Liver Int 2017;37 Suppl 1:85-89.

10. Kleiner DE, Brunt EM, Van Natta M, Behling C, Contos MJ, Cummings OW, et al. Design and validation of a histological scoring system for nonalcoholic fatty liver disease. Hepatology 2005;41:13131321.

11. Hagström H, Nasr P, Ekstedt M, Hammar U, Stål P, Hultcrantz R, et al. Fibrosis stage but not NASH predicts mortality and time to development of severe liver disease in biopsy-proven NAFLD. Hepatol 2017;67:1265-1273.

12. Stål P. Liver fibrosis in non-alcoholic fatty liver disease - diagnostic challenge with prognostic significance. World J Gastroenterol 2015;21:11077-11087.

13. Dulai PS, Singh S, Patel J, Soni M, Prokop LJ, Younossi Z, et al. Increased risk of mortality by fibrosis stage in nonalcoholic fatty liver disease: systematic review and meta-analysis. Hepatology 2017;65:1557-1565.

14. Chitturi S, Farrell GC, Hashimoto E, Saibara T, Lau GK, Sollano JD, et al. Non-alcoholic fatty liver disease in the Asia-Pacific region: definitions and overview of proposed guidelines. J Gastroenterol Hepatol 2007;22:778-787.

15. Ratziu V, Charlotte F, Heurtier A, Gombert S, Giral P, Bruckert E, et al. Sampling variability of liver biopsy in nonalcoholic fatty liver disease. Gastroenterology 2005;128:1898-1906.

16. Mikolasevic I, Orlic L, Franjic N, Hauser G, Stimac D, Milic S. Transient elastography (FibroScan( $($ )) with controlled attenuation parameter in the assessment of liver steatosis and fibrosis in patients with nonalcoholic fatty liver disease - where do we stand? World J Gastroenterol 2016;22:7236-7251.

17. Myers RP, Pollett A, Kirsch R, Pomier-Layrargues $G$, Beaton $M$, Levstik $M$, et al. Controlled Attenuation Parameter (CAP): a noninvasive method for the detection of hepatic steatosis based on transient elastography. Liver Int 2012;32:902-910.

18. Sasso M, Beaugrand $M$, de Ledinghen $V$, Douvin C, Marcellin P, Poupon $\mathrm{R}$, et al. Controlled attenuation parameter (CAP): a novel VCTETM guided ultrasonic attenuation measurement for the evaluation of hepatic steatosis: preliminary study and validation in a 
cohort of patients with chronic liver disease from various causes. Ultrasound Med Biol 2010;36:1825-1835.

19. Sasso M, Tengher-Barna I, Ziol M, Miette V, Fournier C, Sandrin $L$, et al. Novel controlled attenuation parameter for noninvasive assessment of steatosis using Fibroscan(®): validation in chronic hepatitis C. J Viral Hepat 2012;19:244-253.

20. de Lédinghen V, Vergniol J, Foucher J, Merrouche W, le Bail B. Noninvasive diagnosis of liver steatosis using controlled attenuation parameter (CAP) and transient elastography. Liver Int 2012;32:911918.

21. Chan WK, Nik Mustapha NR, Mahadeva S. Controlled attenuation parameter for the detection and quantification of hepatic steatosis in nonalcoholic fatty liver disease. J Gastroenterol Hepatol 2014;29:1470-1476.

22. Shen F, Zheng RD, Mi YQ, Wang XY, Pan Q, Chen GY, et al. Controlled attenuation parameter for non-invasive assessment of hepatic steatosis in Chinese patients. World J Gastroenterol 2014;20:4702-4711.

23. Chon YE, Jung KS, Kim SU, Park JY, Park YN, Kim DY, et al. Controlled attenuation parameter (CAP) for detection of hepatic steatosis in patients with chronic liver diseases: a prospective study of a native Korean population. Liver Int 2014;34:102-109.

24. Mi YQ, Shi QY, Xu L, Shi RF, Liu YG, Li P, et al. Controlled attenuation parameter for noninvasive assessment of hepatic steatosis

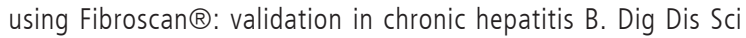
2015;60:243-251.

25. Imajo K, Kessoku T, Honda Y, Tomeno W, Ogawa Y, Mawatari H, et al. Magnetic resonance imaging more accurately classifies steatosis and fibrosis in patients with nonalcoholic fatty liver disease than transient elastography. Gastroenterology 2016;150:626-637.e7.

26. de Lédinghen V, Wong GL, Vergniol J, Chan HL, Hiriart JB, Chan AW, et al. Controlled attenuation parameter for the diagnosis of steatosis in non-alcoholic fatty liver disease. J Gastroenterol Hepatol 2016:31:848-855.

27. Park CC, Nguyen P, Hernandez C, Bettencourt R, Ramirez K, Fortney $L$, et al. Magnetic resonance elastography vs transient elastography in detection of fibrosis and noninvasive measurement of steatosis in patients with biopsy-proven nonalcoholic fatty liver disease. Gastroenterology 2017;152:598-607.e2.

28. Chan WK, Nik Mustapha NR, Mahadeva S, Wong VW, Cheng JY, Wong GL. Can the same controlled attenuation parameter cut-offs be used for $\mathrm{M}$ and $\mathrm{XL}$ probes for diagnosing hepatic steatosis? J Gastroenterol Hepatol 2018;33:1787-1794.

29. Garg H, Aggarwal S, Shalimar, Yadav R, Datta Gupta S, Agarwal $\mathrm{L}$, et al. Utility of transient elastography (fibroscan) and impact of bariatric surgery on nonalcoholic fatty liver disease (NAFLD) in morbidly obese patients. Surg Obes Relat Dis 2018;14:81-91.

30. Siddiqui MS, Vuppalanchi R, Van Natta ML, Hallinan E, Kowdley
$\mathrm{KV}$, Abdelmalek $\mathrm{M}$, et al. Vibration-controlled transient elastography to assess fibrosis and steatosis in patients with nonalcoholic fatty liver disease. Clin Gastroenterol Hepatol 2019;17:156-163.e2.

31. Eddowes PJ, Sasso M, Allison M, Tsochatzis E, Anstee QM, Sheridan $D$, et al. Accuracy of FibroScan controlled attenuation parameter and liver stiffness measurement in assessing steatosis and fibrosis in patients with nonalcoholic fatty liver disease. Gastroenterology 2019;156:1717-1730.

32. Karlas $T$, Petroff $D$, Sasso $M$, Fan JG, Mi YQ, de Lédinghen $V$, et al. Individual patient data meta-analysis of controlled attenuation parameter (CAP) technology for assessing steatosis. J Hepatol 2017;66:1022-1030.

33. Springer F, Machann J, Claussen CD, Schick F, Schwenzer NF. Liver fat content determined by magnetic resonance imaging and spectroscopy. World I Gastroenterol 2010;16:1560-1566.

34. Caussy C, Alquiraish MH, Nguyen P, Hernandez C, Cepin S, Fortney $L E$, et al. Optimal threshold of controlled attenuation parameter with MRI-PDFF as the gold standard for the detection of hepatic steatosis. Hepatology 2018;67:1348-1359.

35. Loomba R, Sirlin CB, Ang B, Bettencourt R, Jain R, Salotti J, et al. Ezetimibe for the treatment of nonalcoholic steatohepatitis: assessment by novel magnetic resonance imaging and magnetic resonance elastography in a randomized trial (MOZART trial). Hepatology 2015;61:1239-1250.

36. Ferraioli $G$, Tinelli $C$, Lissandrin R, Zicchetti $M$, Rondanelli $M$, Perani $G$, et al. Interobserver reproducibility of the controlled attenuation parameter (CAP) for quantifying liver steatosis. Hepatol Int 2014;8:576-581.

37. Saadeh S, Younossi ZM, Remer EM, Gramlich T, Ong JP, Hurley M, et al. The utility of radiological imaging in nonalcoholic fatty liver disease. Gastroenterology 2002;123:745-750.

38. de Lédinghen V, Vergniol J, Capdepont M, Chermak F, Hiriart JB, Cassinotto $C$, et al. Controlled attenuation parameter (CAP) for the diagnosis of steatosis: a prospective study of 5323 examinations. J Hepatol 2014;60:1026-1031.

39. Kwok R, Choi KC, Wong GL, Zhang Y, Chan HL, Luk AO, et al. Screening diabetic patients for non-alcoholic fatty liver disease with controlled attenuation parameter and liver stiffness measurements: a prospective cohort study. Gut 2016;65:1359-1368.

40. Shi KQ, Tang JZ, Zhu XL, Ying L, Li DW, Gao J, et al. Controlled attenuation parameter for the detection of steatosis severity in chronic liver disease: a meta-analysis of diagnostic accuracy. J Gastroenterol Hepatol 2014;29:1149-1158.

41. Sandrin L, Fourquet B, Hasquenoph JM, Yon S, Fournier C, Mal F, et al. Transient elastography: a new noninvasive method for assessment of hepatic fibrosis. Ultrasound Med Biol 2003;29:1705-1713.

42. Petta S, Wong VW, Cammà C, Hiriart JB, Wong GL, Marra F, et al. Improved noninvasive prediction of liver fibrosis by liver stiffness 
measurement in patients with nonalcoholic fatty liver disease accounting for controlled attenuation parameter values. Hepatology 2017;65:1145-1155.

43. Castera L, Forns $X$, Alberti A. Non-invasive evaluation of liver fibrosis using transient elastography. J Hepatol 2008;48:835-847.

44. Ziol M, Handra-Luca A, Kettaneh A, Christidis C, Mal F, Kazemi $F$, et al. Noninvasive assessment of liver fibrosis by measurement of stiffness in patients with chronic hepatitis C. Hepatology 2005;41:48-54.

45. Chan HL, Wong GL, Choi PC, Chan AW, Chim AM, Yiu KK, et al. Alanine aminotransferase-based algorithms of liver stiffness measurement by transient elastography (Fibroscan) for liver fibrosis in chronic hepatitis B. J Viral Hepat 2009;16:36-44.

46. Yoneda $M$, Yoneda $M$, Mawatari $H$, Fujita $K$, Endo $H$, lida $H$, et al. Noninvasive assessment of liver fibrosis by measurement of stiffness in patients with nonalcoholic fatty liver disease (NAFLD). Dig Liver Dis 2008;40:371-378.

47. Wong VW, Vergniol J, Wong GL, Foucher J, Chan HL, Le Bail B, et al. Diagnosis of fibrosis and cirrhosis using liver stiffness measurement in nonalcoholic fatty liver disease. Hepatology 2010;51:454-462.

48. Gaia S, Carenzi S, Barilli AL, Bugianesi E, Smedile A, Brunello F, et al. Reliability of transient elastography for the detection of fibrosis in non-alcoholic fatty liver disease and chronic viral hepatitis. J Hepatol 2011;54:64-71.

49. Wong VW, Vergniol J, Wong GL, Foucher J, Chan AW, Chermak F, et al. Liver stiffness measurement using XL probe in patients with nonalcoholic fatty liver disease. Am J Gastroenterol 2012;107:18621871.

50. Kumar R, Rastogi A, Sharma MK, Bhatia V, Tyagi P, Sharma P, et al. Liver stiffness measurements in patients with different stages of nonalcoholic fatty liver disease: diagnostic performance and clinicopathological correlation. Dig Dis Sci 2013;58:265-274.

51. Lee HW, Park SY, Kim SU, Jang JY, Park H, Kim JK, et al. Discrimination of nonalcoholic steatohepatitis using transient elastography in patients with nonalcoholic fatty liver disease. PLoS One 2016;11:e0157358.

52. Talwalkar JA, Kurtz DM, Schoenleber SJ, West CP, Montori VM. UItrasound-based transient elastography for the detection of hepatic fibrosis: systematic review and meta-analysis. Clin Gastroenterol Hepatol 2007;5:1214-1220.

53. Fraquelli M, Rigamonti C, Casazza G, Conte D, Donato MF, Ronchi $\mathrm{G}$, et al. Reproducibility of transient elastography in the evaluation of liver fibrosis in patients with chronic liver disease. Gut 2007;56:968-973.

54. Hu Z, Li Y, Li C, Huang C, Ou Z, Guo J, et al. Using ultrasonic transient elastometry (FibroScan) to predict esophageal varices in patients with viral liver cirrhosis. Ultrasound Med Biol 2015;41:15301537.
55. Wang JH, Chuah SK, Lu SN, Hung CH, Chen $\mathrm{CH}$, Kee KM, et al. Transient elastography and simple blood markers in the diagnosis of esophageal varices for compensated patients with hepatitis $B$ virus-related cirrhosis. J Gastroenterol Hepatol 2012;27:1213-1218.

56. Pritchett S, Cardenas A, Manning D, Curry M, Afdhal NH. The optimal cut-off for predicting large oesophageal varices using transient elastography is disease specific. J Viral Hepat 2011;18:e75-e80.

57. de Franchis R; Baveno VI Faculty. Expanding consensus in portal hypertension: report of the Baveno VI Consensus Workshop: stratifying risk and individualizing care for portal hypertension. J Hepatol 2015;63:743-752.

58. Petta S, Sebastiani G, Bugianesi E, Viganò M, Wong VW, Berzigotti $A$, et al. Non-invasive prediction of esophageal varices by stiffness and platelet in non-alcoholic fatty liver disease cirrhosis. J Hepatol 2018;69:878-885.

59. Masuzaki R, Tateishi R, Yoshida H, Goto E, Sato T, Ohki T, et al. Prospective risk assessment for hepatocellular carcinoma development in patients with chronic hepatitis $\mathrm{C}$ by transient elastography. Hepatology 2009;49:1954-1961.

60. Kim MN, Kim SU, Park JY, Kim DY, Han KH, Chon CY, et al. Risk assessment of liver-related events using transient elastography in patients with chronic hepatitis B receiving entecavir. J Clin Gastroenterol 2014;48:272-278.

61. Chon YE, Jung ES, Park JY, Kim DY, Ahn SH, Han KH, et al. The accuracy of noninvasive methods in predicting the development of hepatocellular carcinoma and hepatic decompensation in patients with chronic hepatitis B. J Clin Gastroenterol 2012;46:518-525.

62. Singh S, Fujii LL, Murad MH, Wang Z, Asrani SK, Ehman RL, et al. Liver stiffness is associated with risk of decompensation, liver cancer, and death in patients with chronic liver diseases: a systematic review and meta-analysis. Clin Gastroenterol Hepatol 2013;11:1573-1584.e1-e2; quiz e88-e89.

63. Pang JX, Zimmer S, Niu S, Crotty P, Tracey J, Pradhan F, et al. Liver stiffness by transient elastography predicts liver-related complications and mortality in patients with chronic liver disease. PLoS One 2014;9:e95776.

64. Liu K, Wong VW, Lau K, Liu SD, Tse YK, Yip TC, et al. Prognostic value of controlled attenuation parameter by transient elastography. Am J Gastroenterol 2017;112:1812-1823.

65. Ekstedt $M$, Hagström $H$, Nasr P, Fredrikson M, Stål $P$, Kechagias $S$, et al. Fibrosis stage is the strongest predictor for disease-specific mortality in NAFLD after up to 33 years of follow-up. Hepatology 2015;61:1547-1554.

66. Kwok R, Tse YK, Wong GL, Ha Y, Lee AU, Ngu MC, et al. Systematic review with meta-analysis: non-invasive assessment of non-alcoholic fatty liver disease--the role of transient elastography and plasma cytokeratin-18 fragments. Aliment Pharmacol Ther 2014;39:254-269. 
67. Wong GL, Wong VW, Choi PC, Chan AW, Chim AM, Yiu KK, et al. On-treatment monitoring of liver fibrosis with transient elastography in chronic hepatitis B patients. Antivir Ther 2011;16:165-172.

68. Wang JH, Changchien CS, Hung CH, Tung WC, Kee KM, Chen $\mathrm{CH}$, et al. Liver stiffness decrease after effective antiviral therapy in patients with chronic hepatitis C: longitudinal study using FibroScan. J Gastroenterol Hepatol 2010;25:964-969.

69. Koehler EM, Plompen EP, Schouten JN, Hansen BE, Darwish Murad $S$, Taimr $P$, et al. Presence of diabetes mellitus and steatosis is associated with liver stiffness in a general population: the Rotterdam study. Hepatology 2016;63:138-147.

70. Stafylidou M, Paschos P, Katsoula A, Malandris K, loakim K, Bekiari $\mathrm{E}$, et al. Performance of Baveno VI and expanded Baveno VI criteria for excluding high-risk varices in patients with chronic liver diseases: a systematic review and meta-analysis. Clin Gastroenterol Hepatol 2019;17:1744-1755.e11.

71. Zeng J, Cai S, Liu J, Xue X, Wu X, Zheng C. Dynamic changes in liver stiffness measured by transient elastography predict clinical outcomes among patients with chronic hepatitis B. J Ultrasound Med 2017;36:261-268.

72. Elsharkawy A, Alem SA, Fouad R, El Raziky M, El Akel W, Abdo M, et al. Changes in liver stiffness measurements and fibrosis scores following sofosbuvir based treatment regimens without interferon. J Gastroenterol Hepatol 2017;32:1624-1630.

73. Wong GL, Wong VW, Chim AM, Yiu KK, Chu SH, Li MK, et al. Factors associated with unreliable liver stiffness measurement and its failure with transient elastography in the Chinese population. J Gastroenterol Hepatol 2011;26:300-305.

74. Wei JL, Leung JC, Loong TC, Wong GL, Yeung DK, Chan RS, et al. Prevalence and severity of nonalcoholic fatty liver disease in nonobese patients: a population study using proton-magnetic resonance spectroscopy. Am J Gastroenterol 2015;110:1306-1314; quiz 1315.

75. Wong VW, Chan HL. Transient elastography. J Gastroenterol Hepatol 2010;25:1726-1731.

76. de Lédinghen V, Wong VW, Vergniol J, Wong GL, Foucher J, Chu $\mathrm{SH}$, et al. Diagnosis of liver fibrosis and cirrhosis using liver stiffness measurement: comparison between $\mathrm{M}$ and $\mathrm{XL}$ probe of FibroScan®. J Hepatol 2012;56:833-839.

77. Myers RP, Pomier-Layrargues G, Kirsch R, Pollett A, Duarte-Rojo $A$, Wong $D$, et al. Feasibility and diagnostic performance of the FibroScan XL probe for liver stiffness measurement in overweight and obese patients. Hepatology 2012;55:199-208.

78. Wong VW, Irles M, Wong GL, Shili S, Chan AW, Merrouche W, et al. Unified interpretation of liver stiffness measurement by $M$ and XL probes in non-alcoholic fatty liver disease. Gut 2019;68:20572064.

79. Myers RP, Pomier-Layrargues $G$, Kirsch R, Pollett A, Beaton M,
Levstik $M$, et al. Discordance in fibrosis staging between liver biopsy and transient elastography using the FibroScan XL probe. J Hepatol 2012;56:564-570.

80. Boursier J, Zarski JP, de Ledinghen V, Rousselet MC, Sturm N, Le Bail $B$, et al. Determination of reliability criteria for liver stiffness evaluation by transient elastography. Hepatology 2013;57:11821191.

81. Loong TC, Wei JL, Leung JC, Wong GL, Shu SS, Chim AM, et al. Application of the combined FibroMeter vibration-controlled transient elastography algorithm in Chinese patients with non-alcoholic fatty liver disease. J Gastroenterol Hepatol 2017;32:1363-1369.

82. Wong VW, Petta S, Hiriart JB, Cammà C, Wong GL, Marra F, et al. Validity criteria for the diagnosis of fatty liver by $\mathrm{M}$ probe-based controlled attenuation parameter. J Hepatol 2017;67:577-584.

83. Millonig G, Friedrich S, Adolf S, Fonouni H, Golriz M, Mehrabi A, et al. Liver stiffness is directly influenced by central venous pressure. J Hepatol 2010;52:206-210.

84. Hopper I, Kemp W, Porapakkham P, Sata Y, Condon E, Skiba M, et al. Impact of heart failure and changes to volume status on liver stiffness: non-invasive assessment using transient elastography. Eur J Heart Fail 2012;14:621-627.

85. Millonig G, Reimann FM, Friedrich S, Fonouni $H$, Mehrabi A, Büchler MW, et al. Extrahepatic cholestasis increases liver stiffness (FibroScan) irrespective of fibrosis. Hepatology 2008;48:17181723.

86. Lanzi A, Gianstefani A, Mirarchi MG, Pini P, Conti F, Bolondi L. Liver AL amyloidosis as a possible cause of high liver stiffness values. Eur J Gastroenterol Hepatol 2010;22:895-897.

87. Wong GL, Kwok R, Wong VW. Huge adrenal hemangioma: a rare cause of deceivingly high liver stiffness measurement by transient elastography. Clin Gastroenterol Hepatol 2015;13:e37-e38.

88. Ferraioli G, Wong VW, Castera L, Berzigotti A, Sporea I, Dietrich $C F$, et al. Liver ultrasound elastography: an update to the world federation for ultrasound in medicine and biology guidelines and recommendations. Ultrasound Med Biol 2018;44:2419-2440.

89. Arena U, Lupsor Platon M, Stasi C, Moscarella S, Assarat A, Bedogni $G$, et al. Liver stiffness is influenced by a standardized meal in patients with chronic hepatitis $C$ virus at different stages of fibrotic evolution. Hepatology 2013;58:65-72.

90. Arena U, Vizzutti F, Corti G, Ambu S, Stasi C, Bresci S, et al. Acute viral hepatitis increases liver stiffness values measured by transient elastography. Hepatology 2008;47:380-384.

91. Wong GL, Wong VW, Choi PC, Chan AW, Chim AM, Yiu KK, et al. Increased liver stiffness measurement by transient elastography in severe acute exacerbation of chronic hepatitis B. J Gastroenterol Hepatol 2009;24:1002-1007.

92. Wong VW, Wong GL, Tsang SW, Hui AY, Chan AW, Choi PC, et al. Metabolic and histological features of non-alcoholic fatty liver dis- 
Xinrong Zhang, et al. Transient elastography in fatty liver

ease patients with different serum alanine aminotransferase levels. Aliment Pharmacol Ther 2009;29:387-396.

93. Petta S, Maida M, Macaluso FS, Di Marco V, Cammà C, Cabibi D, et al. The severity of steatosis influences liver stiffness measurement in patients with nonalcoholic fatty liver disease. Hepatology 2015;62:1101-1110.

94. Wong GL, Chan HL, Choi PC, Chan AW, Lo AO, Chim AM, et al. Association between anthropometric parameters and measurements of liver stiffness by transient elastography. Clin Gastroenterol Hepatol 2013;11:295-302.e1-e3.

95. Chalasani N, Younossi Z, Lavine JE, Charlton M, Cusi K, Rinella M, et al. The diagnosis and management of nonalcoholic fatty liver disease: practice guidance from the American Association for the Study of Liver Diseases. Hepatology 2018;67:328-357.

96. European Association for the Study of the Liver (EASL); European
Association for the Study of Diabetes (EASD); European Association for the Study of Obesity (EASO). EASL-EASD-EASO clinical practice guidelines for the management of non-alcoholic fatty liver disease. J Hepatol 2016;64:1388-1402.

97. European Association for Study of Liver; Asociacion Latinoamericana para el Estudio del Higado. EASL-ALEH clinical practice guidelines: non-invasive tests for evaluation of liver disease severity and prognosis. J Hepatol 2015;63:237-264.

98. Srivastava A, Gailer R, Tanwar S, Trembling P, Parkes J, Rodger $A$, et al. Prospective evaluation of a primary care referral pathway for patients with non-alcoholic fatty liver disease. J Hepatol 2019;71:371-378.

99. Yoneda M, Yoneda M, Fujita K, Inamori M, Tamano M, Hiriishi H, et al. Transient elastography in patients with non-alcoholic fatty liver disease (NAFLD). Gut 2007;56:1330-1331. 